\title{
CENAS ENUNCIATIVAS EM REDES SOCIAIS: DIREÇÕES ARGUMENTATIVAS E(M) IMPLICAÇÕES PARA O ENSINO
}

\author{
Nádia Dolores Fernandes Biavati ${ }^{1}$ \\ (1) https://orcid.org/0000-0002-3119-793X \\ Jéssica Soares de Resende ${ }^{2}$ \\ (1) https://orcid.org/0000-0002-0576-2042
}

Resumo: 0 presente texto visa demostrar os resultados da análise enunciativa sobre o acontecimento Programa Nacional das Escolas Cívico-Militares destacados na rede social Facebook. Nossa abordagem aponta para argumentos que corroboram (ou não) fundamentos, valores e ações defendidas em uma visão em que se destacam movimentos enunciativos, presentes nas redes sociais, decorrentes de: (i) divulgação do Programa Nacional das Escolas Cívico-Militares em que se noticia a instalação de 216 novos colégios até $2023 \mathrm{e}(\mathrm{m})$ suas repercussões; (ii) os comentários à postagem na fanpage Facebook. Desse modo, tomam-se os argumentos e o modo como a instituição escolar e as escolhas enunciativas como disciplina, ordem, qualidade e hierarquia norteiam a postagem e projetam sentidos a partir da temática. Percebeu-se a importância de abordar os discursos que perpassam a escola atual e o modo como os leitores precisam se manifestar com argumentos favoráveis e contrários construídos a partir dos comentários de postagem, indicando os valores de uma escola e a educação ideais (ou não), conforme o debate instaurado sobre o assunto, norteando ações possíveis para os professores diante desse debate.

Palavras-chave: argumentação; comentários; movimentos enunciativos.

${ }^{1}$ Doutora em Estudos Linguísticos pela Universidade Federal de Minas Gerais (UFMG). Pósdoutoranda na UFMG. Professora da Universidade Federal de São João del-Rei (UFSJ). E-mail: nadiabiavati@ufsj.edu.br.

${ }^{2}$ Graduada em Letras pela Universidade Federal de São João del-Rei (UFSJ). E-mail: jessicaresende22@outlook.com. 


\title{
ENUNCIATIVE SCENES IN SOCIAL NETWORKS: ARGUMENTATIVE DIRECTIONS AND IMPLICATIONS FOR TEACHING
}

\begin{abstract}
This paper aims to demonstrate the results of the enunciative analysis about the event National Program of Civic-Military Schools highlighted in the social network Facebook. Our approach points to arguments that corroborate (or not) fundamentals, values and actions defended in a vision in which enunciative movements, present in social networks, are highlighted, arising from: (i) disclosure of the National Program of CivicMilitary Schools in which the installation of 216 new schools by 2023 is reported and(m) its repercussions; (ii) the comments to the post on the Facebook fanpage. Thus, the arguments and the way the school institution and enunciative choices such as discipline, order, quality and hierarchy guide the post and project meanings from the theme are taken. It was noticed the importance of addressing the discourses that permeate the current school and how readers need to manifest themselves with favorable and contrary arguments built from the post comments, indicating the values of a school and the ideal education (or not), according to the debate instaured on the subject, guiding possible actions for teachers before this debate.
\end{abstract}

Keywords: argumentation; comments; enunciative movements.

\section{ESCENAS ENUNCIATIVAS EN LAS REDES SOCIALES: DIRECCIONES ARGUMENTATIVAS E(M) IMPLICACIONES PARA LA ENSEÑANZA}

Resumen: El presente texto tiene como objetivo demostrar los resultados del análisis enunciativo sobre el evento Programa Nacional de Escuelas Cívico-Militares destacado en la red social Facebook. Nuestro enfoque apunta a los argumentos que corroboran (o no) los fundamentos, valores y acciones defendidos en una visión en la que se destacan los movimientos enunciativos, presentes en las redes sociales, que surgen de: (i) la divulgación del Programa Nacional de Escuelas Cívico-Militares en el que se informa de la instalación de 216 nuevas escuelas hasta el año 2023 y(m) sus repercusiones; (ii) los comentarios al post en la fanpage de Facebook. Así, se toman los argumentos y la forma en que la institución escolar y las opciones enunciativas como la disciplina, el orden, la calidad y la jerarquía orientan el puesto y proyectan significados a partir del tema. Se notó la importancia de abordar los discursos que permean la escuela actual y cómo los lectores necesitan manifestarse con argumentos favorables y contrarios construidos a partir de los comentarios de los correos, indicando los valores de una escuela y la educación ideal (o no), de acuerdo al debate establecido sobre el tema, orientando posibles acciones para los docentes ante este debate.

Palabras clave: argumentación; comentarios; movimientos enunciativos. 


\section{Introdução}

O presente trabalho busca observar o modo como dois movimentos enunciativos são construídos em vinte comentários retirados da rede social Facebook, quando o Programa Nacional das Escolas Cívico-Militares é apresentado e comentado, em 2019. A ideia é observar como as pessoas manifestam valores e discursos sobre a escola do modelo vigente representada em oposição à escola com a intervenção cívico-militar. Para a análise, considera-se o que se refere à leitura, à argumentação e o tratamento às cenas enunciativas, bem como aos aspectos discursivos que corroboram os resultados e o modo como eles podem repercutir no ensino.

Entendemos que costuma ser um desafio para o aluno ler um texto e perceber como se dá o ponto de vista que nele se defende. Por outro lado, tal desafio deixa de existir quando deixamos de exercitar a leitura como objeto de simples decodificação. Usar o conhecimento de leitura como desvendamento de frases e ideias não é suficiente para que a compreensão e a interpretação se efetivem. Há que considerar como ponto importante na interpretação a habilidade no tratamento do gênero e o conhecimento pelo qual se permite reconhecer o vocabulário, as ligações e os efeitos de sentidos que se dão quando acionamos as estratégias linguísticas e não linguísticas utilizadas nessa construção.

$\mathrm{Na}$ visão enunciativo - discursiva com a qual trabalhamos, o falante produz conhecimentos que estão para além da simples leitura, pois é necessário conceber relações que dialogam com a historicidade. Entendemos que há espaços que se preenchem quando percebemos o que está em jogo ao enunciar: toma-se um tema, escolhem-se formas de dizer sobre um assunto em enunciados e defende-se uma visão de mundo. Na análise de discurso, reivindicamos que os gêneros carregam posturas ou ideologias defendidas que interpelam os sujeitos, ainda que sutilmente, ao reivindicar determinada posição. Portanto, cabe ao professor desafiar o aluno a identificar quais posições são essas, além de desvelar as relações que podem atravessar o ponto de vista A ou o ponto de vista B e suas diferenças.

Ao abordar leituras com o aluno, é necessário, antes de tudo, destacar como deve acontecer o exercício de ler. Na escola, em geral, especialmente na segunda etapa do ensino fundamental, surgem elementos textuais que chamam atenção para o argumentar. Ler um post em sua totalidade é observar não somente enunciados e (no 
caso) ilustração, mas também comentários (que acabam por se tornar um gênero à parte). No caso em questão, tais comentários seguem após o anúncio do programa que evidencia as escolas cívico-militares, defendidas pelo ministério da educação de 2019, e sua expansão.

Os comentários são, portanto, a fonte da maioria dos argumentos que contemplam a necessidade de perceber os posicionamentos na construção de pontos de vista. Com isso, tomamos a argumentação como um ponto de reconhecimento na leitura para o emprego de estratégias linguísticas e enunciativas, que reivindicam o exercício de perceber os caminhos trilhados na elaboração e na visibilização de pontos de vista.

Para nós, vale a visão para além da que propõe a argumentação como estratégia retórica. Nesse viés, a argumentação tem seu lugar na linguagem (ORLANDI, 1998) como modo de manifestação por meio das linguagens escrita e visual, definitiva para evocar posicionamentos, para além do plano estético.

A partir disso, busca-se expor nesse texto uma concepção de argumentação tendo em vista a caracterização daquele que argumenta, bem como as implicações dos comentários em posts e como tais implicações podem repercutir no ensino, se constituindo como um gênero importante para a observação em sala devido ao seu poder de trazer força à palavra, conforme tratamos em pontos da análise que repercutem no ensino.

\section{Argumentação em sala de aula: o exercício do diálogo}

Segundo a semântica da enunciação, a argumentação acontece nos espaços da enunciação, o que significa que a língua funciona na relação com outras línguas e seus falantes. Partimos da leitura dos trabalhos de Ducrot (2009) e Ducrot e Carel (2006) sobre argumentação para avançar na noção de argumentação para além do olhar à retórica e tomamos o caminho da relação de sentidos que orienta o dizer, conforme explica Guimarães (2013).

Desse modo, tomamos como base o olhar de Guimarães (2013, p. 272), ao afirmar que "[...] no espaço de enunciação, o falante não é, de acordo com minha posição, um ser psicofisiológico, mas é uma figura determinada por sua relação com as línguas, a qual constitui o falante". O falante é, então, constituído no espaço da 
enunciação, tornando-se o locutor, que está relacionado com os sistemas da língua e com os falantes que se posicionam como locutores. Essa relação estabelecida entre sujeitos caracteriza uma relação política e histórica com a língua, destacando-se o que defende Orlandi (1998, p. 74) sobre o viés político aqui problematizado: “0 político compreendido discursivamente significa que o sentido é sempre dividido, sendo que esta divisão tem uma direção que não é indiferente às injunções das relações de força que derivam da forma da sociedade na história".

Essa relação histórica e política pode ser observada no que diz respeito às divisões das línguas e dos falantes em relação aos direitos do dizer, aos modos de dizer e às posições ideológicas assumidas, que os determinam como base na constituição das relações argumentativas. 0 político se dá não por partidarismos, mas por conflitos que se fazem a partir da força do dizer.

A construção argumentativa se dá nas chamadas cenas enunciativas, as quais, segundo Guimarães (2013), se constituem "[...] por um conjunto de figuras da enunciação que, de algum modo, 'falam' no acontecimento". Assim, entendemos que as direções do dizer participam da cena enunciativa, pois são elas que constroem esses locais nos espaços enunciativos (GUIMARÃES, 2002) em que se projetam os sujeitos no agenciamento da palavra, em suas escolhas, em sua forma de pensar o mundo e na maneira como defendem e separam essas relações.

As cenas enunciativas se projetam de lugares de dizer temporalizados e especificados no acontecimento (DALMASCHIO; JAMAL, 2014). Dessa forma, é importante compreender as forças que se projetam no post para apoiar e para não apoiar a implantação e a expansão das escolas cívico-militares como parte do projeto enunciativo que segue a postagem.

Observar os lugares de dizer e como cada posição se dá são atitudes didatizadoras importantes em uma aula de português, pois as forças opostas (que investem ora a favor, ora contra o programa) observadas no post e nos comentários trazem à baila as marcas do dizer a partir de posições argumentativamente assumidas em condições histórico-enunciativas. Assim, os alunos devem ser desafiados a registrar e justificar sua posição, compreendendo seu papel crítico na compreensão do acontecimento de linguagem. Cada acontecimento projeta posições que resvalam nos discursos, traduzindo enunciados em enunciações. 
Tomamos em destaque a enunciação que atravessa o acontecimento implantação e defesa (ou não) das escolas cívico-militares na postagem ou no que nomeamos como conjunto post/comentários. 0 fato retratado no post se dá na temporalidade do dia 5 de setembro de 2019, quando o governo federal lançou o Programa Nacional das Escolas Cívico-Militares, anunciando a criação de 216 novas escolas até 2023, anunciando o objetivo de promover a melhoria na educação básica do País. Em pauta, indiretamente e opostamente marcando os comentários, a defesa ao presidente Jair Messias Bolsonaro (militar), bem como o caráter disciplinar, importante para as escolas com tutela de militares e a desaprovação ao projeto por leitores que criticam o regime dessas escolas.

O fato destaca a cena enunciativa, que é marcada por ser o lugar e o tempo em que ocorre a enunciação realizada pelo locutor, que ocupa um lugar social que lhe permite ou não dizer algo, enquanto se projeta um interlocutor, que também ocupa um lugar social.

A cena enunciativa é, então, construída a partir das relações entre o locutor/alocutário e o enunciador/destinatário, em que o locutor, função exercida no anúncio contido na postagem, apresenta uma relação de sentidos para seu alocutário. Interessam, portanto, não só a simples divulgação da criação de escolas militares e a expansão desse processo, mas também a posição do locutor (representante governamental - presidente) e os discursos originários da defesa do programa.

Nesse sentido, a partir da cena enunciativa que coloca em primeiro plano a implantação de escolas militares, o post destaca a fanpage do MEC na rede social Facebook. Na postagem que se coloca em anúncio, verificam-se dois movimentos enunciativos tomando o acesso à palavra em dois conjuntos de posições, que conflituam nas redes sociais em direção à notícia: um deles é apoiar a implementação das escolas; o outro é não apoiar a implementação das escolas.

Dias (2015) toma as cenas enunciativas como dinâmicas específicas de acesso à palavra: elas indicam os lugares de enunciação em que as formas são mobilizadas nas interações. Essa apresentação de relações de sentidos do locutor para seu alocutário é o que se define como orientação argumentativa, porque assim o acontecimento pode convergir para as posições constituídas na enunciação dos ocupantes de uma posição social. Conforme o modo de dizer, sustentam-se posições que levam a uma conclusão. 
Nos comentários a ser analisados, percebe-se que as direções argumentativas são conflitantes, uma vez que as argumentações, assim como os sentidos aplicados a determinados conceitos, diferem entre si e se apoiam em fontes diferentes.

Guimarães (2013, p. 283) define a argumentação como o “[...] processo pelo qual um lugar social de locutor sustenta uma posição na enunciação". E como defende o autor, a argumentação não significa um exercício retórico, em que o locutor apresenta razões e não provas de alguma coisa e, do mesmo modo, visa sustentar sua conclusão e não persuadir. Assim, a argumentação em materialidade toma como fontes a língua, a enunciação e o discurso, os quais permitem direcionar o dizer para uma conclusão. Portanto, a busca da significação quer dizer ir além do caráter persuasivo da argumentação, conforme explica Guimarães (2013, p. 277): “Assim, a argumentatividade linguística nada tem a ver com a consideração da argumentação como a busca da persuasão ou convencimento, sendo simplesmente uma significação que orienta, num certo sentido, o dizer".

Dessa forma, a argumentação se constitui na cena enunciativa, em que locutor e alocutário ocupam um lugar social, em que sujeitos demonstram posições, instituem o dizer com escolhas de argumentos. A partir dessa consideração, os argumentos são as razões apresentadas para sustentar determinadas posições, determinadas conclusões. Em síntese, a argumentação se dá em relação própria do lugar social de dizer.

Ao explorar as cenas enunciativas em sala, é importante não se ater a nomenclaturas a partir da teoria enunciativa: o que interessa é destacar o modo como os gêneros se apresentam no mundo e explorar a argumentação.

Para nós, o post é um recorte da realidade que se apresenta em rede social, pois indica as razões dos leitores para apoiar ou condenar uma posição que se manifesta naquele post. $\mathrm{O}$ assunto aqui em discussão é uma adaptação do portal do MEC para se tornar um anúncio no Facebook, rede social em que é postada a notícia sobre a implantação/expansão do programa de escolas cívico-militares. Juntam-se à postagem comentários, a palavra de leitores que se manifestam com o próprio ponto de vista sobre o tema.

Ao evocar o gênero post de rede social na fanpage governamental para nossa discussão, tomamos a noção bakhtiniana de gênero. Bakhtin (1992) define gênero como "tipos relativamente estáveis de enunciados". Os gêneros apresentam tema, forma de construção linguística típica em um formato para cumprir uma função social 
e um estilo (um modo de dizer) específico que atenda a determinadas expectativas. São construções discursivas ratificadas socialmente que apresentam um modo de produção, de circulação e características de uso de linguagem.

Em suas pesquisas, Luiz Antônio Marcuschi (2008) apresenta vários gêneros como possibilidades da linguagem em ação na vida social, argumentando sobre a importância de eles serem reconhecidos e trabalhados no ensino. 0 trabalho com gênero post pode ser um rico objeto de didatização, pois desafia professor e alunos ao diálogo em que ambos podem comparar e definir sentidos possíveis de construções, estabelecer formas de articulação, estilo e seus efeitos, exercitar a interpretação e a reflexão nas atividades sociais.

A proposta é que o professor explore os gêneros, em especial as direções argumentativas do dito, uma vez que, nesse caso, a fanpage do MEC optou por não limitar os comentários dos leitores que se tornam locutores ao comentar o programa. Por isso, acredita-se que post e comentários, nesse caso, são interdependentes para anunciar as escolas cívico-militares.

Percebe-se que no post predomina o tipo textual descritivo, inclusive porque traz um adendo com a expressão "Para cego ver", que antecede a descrição da postagem destinada a deficientes visuais. Nos comentários apresenta-se uma visão opinativa sobre o conteúdo do post, ou seja, anunciar as escolas cívico-militares que se dá com a postagem paralelamente com os comentários dos leitores. É nesse ponto que o professor deve incentivar o aluno a selecionar visões de mundo por meio dos argumentos ali expostos, visões que, no caso, operam com a defesa das escolas cívicomilitares ou com dizeres que sustentam uma visão que critica a implantação e o apoio a essa forma de escola.

Quanto ao aporte discursivo, consideramos o que Orlandi (2001, p. 153), aponta sobre a atividade estruturante do discurso, pois "[...] um tipo de discurso resulta do funcionamento discursivo, sendo este último definido como a atividade estruturante de um discurso determinado, por um falante determinado, com finalidades específicas". Nesse contexto, acrescentam-se tanto determinações histórico-sociais e ideológicas quanto formas e sentidos que se fazem pela interação, produzindo materialidades que se movimentam na interação.

Eni Orlandi $(2001,2009)$ apresenta o discurso autoritário, em que uma verdade é imposta e marcada pela paráfrase, em que ocorre a permanência do sentido único 
ainda que se manifeste nas diferentes formas. Observa-se, portanto, o funcionamento desse discurso, apontando a maneira como acontecem os argumentos, os valores e as práticas retratados a respeito da escola cívico-militar em oposição às escolas convencionais. A interface dos estudos enunciativo-discursivos ao olhar voltado para o ensino faz avançar para a investigação dos efeitos de sentido a partir das possibilidades trazidas pelas direções argumentativas diferentes.

Considerando-se a argumentação provinda da relação própria do lugar social de dizer em que locutor e alocutário produzem sentidos, tomamos a análise para observar como se dá a construção enunciativa do dizer o modo como o discurso autoritário atua em comentários de posts de redes sociais. Além disso, destaca-se a rede escolar interpelada por discursos sobre a escola e a educação com interfaces para atuação dos aparelhos ideológicos do estado nos dias de hoje, na fanpage.

\section{Material e métodos}

Tomando em destaque o post e os comentários tratamento ao presente texto, chamamos atenção para o modo como se desenrola o fato aos olhos do MEC em rede social. No dia 5 de setembro de 2019, o Ministério da Educação (MEC) divulgou, no post que analisamos e trazemos para discussão, o lançamento do referido Programa Nacional das Escolas Cívico-Militares.

Considerando essa cena enunciativa governamental, observam-se dois movimentos enunciativos opostos e conflitantes nas redes sociais. Apresentam-se dois grupos de argumentos: o primeiro grupo apoia politicamente a criação e a expansão das escolas, a partir de argumentos de que a escola precisa recuperar valores e ideais considerados inexistentes nas escolas atuais, como a disciplina, a ordem e o ensino de qualidade; o segundo grupo questiona tanto o programa quanto o custo da criação e a falta de investimento nas escolas atuais. Diante disso, busca-se compreender os sentidos projetados dos argumentos que se dão em ambas as direções. Para tanto, os comentários coletados foram organizados em dois grupos: grupo 1, composto por argumentações favoráveis à implantação das escolas; e grupo 2, formado por argumentações desfavoráveis à implantação. 
Abordam-se, para a presente análise, comentários retirados de uma publicação feita pelo MEC na rede social Facebook, em que anuncia o lançamento do Programa (Figura 1).

Figura 1 - Postagem na fanpage - 0 anúncio

Ministério da Educaçâo - MEC 5 de set an $15.27+6$

"EscolaCivicoMilitar I O governo federal lançou nesta quinta-feira, 5 de setembro, o Programa Nacional das Escolas CívicoMilitares. Está prevista a implementaçăo de 216 colégios até 2023 - 54 por ano, a começar por 2020. E o dobro do anunciado pelo Ministério da Educaçăo (MEC) no Compromisso Nacional pela EducaçJo Básica, em julho.

Saiba mais: http://bit.ly/2kkBw96

\section{"Pracegover}

$\mathrm{Na}$ imagem, há uma foto com estudantes de escolas civico-militares sorrindo. Abaixo, está escrito: Governo federal lança programa de implantacto de escolas civico-militares. MEC dobra o número de ofertas; serJ̃o duzentas e dezesseis escolas neste modelo até dois mil $\mathrm{e}$ vinte e très.

Escreva um comentário.

Fonte: Brasil (2019).

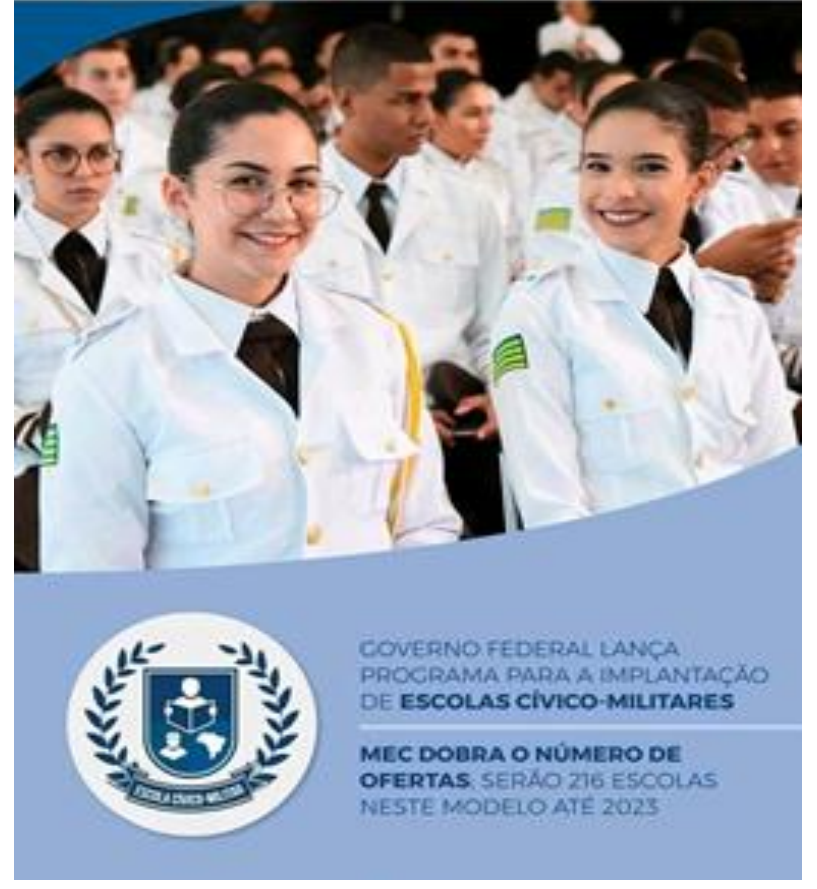

No trabalho com a(s) linguagem(ns) em aula, destacam-se aspectos importantes a ser explorados no processo de didatização: o gênero post e o modo como é comentado em rede social, além da divulgação do programa por meio do post e a quem se destina tal divulgação. 0 público geral tem acesso à fanpage do Ministério da Educação no Facebook.

Abordando os aspectos semióticos do post, percebe-se que a ilustração é importante no processo de percepção dos aspectos divulgados, por isso deve ser explorada em aula, pois se dá como uma forma de linguagem que referenda um posicionamento favorável às escolas em questão. A análise é precedida do processo de didatização do post que será comentado em aula, explorando as posições sobre as escolas cívico-militares, bem como as visões expressas no post e nos comentários. Ao didatizar a aula explorando especialmente os aspectos enunciativos, no primeiro momento, abordam-se as relações entre o plano textual do post, que é um anúncio cuja escrita e ilustração se retroalimentam. Vale comentar que a cena enunciativa se 
constitui em planos de escrita e ilustração, em uma rede de sentidos: nesta apresentam-se alunas felizes, e naquele há o texto em que é apresentado o programa em suas vantagens, rede de valores e ações que se mostram favoráveis ao programa, descrevendo-o nessa direção. Do lado direito, o brasão, como um desenho que identifica o símbolo das escolas anunciadas, importante no tratamento militar/governamental ao programa anunciado.

\section{Argumentação em comentários: o tratamento da materialidade linguística na sala de aula}

Após a apresentação do post e dos comentários que (sugere-se) acontecerá em um primeiro momento com alunos do nono ano do ensino fundamental, é importante que professor e alunos conheçam os diferentes sistemas de ensino, observando o referencial histórico em que se dá o modo de funcionamento das escolas públicas, das escolas particulares e o perfil das escolas públicas cívico-militares, uma vez que esses elementos estão em pauta. Considerando o fato de que em pouco tempo irão para o ensino médio, serão motivados a procurar na Internet e em outras fontes as características de cada modalidade escolar, anotando vantagens e possíveis regras de funcionamento de cada uma: Escola pública de ensino médio; Escola privada de ensino médio; Escola pública cívico-militar (ensino médio).

Em seguida, divididos em grupos, os alunos serão orientados a selecionar os argumentos nos comentários que seguem à postagem. Desse modo, sugerimos a criação de dois grupos de argumentos, representados a seguir nos grupos 1 e 2 (Quadro 1).

Quadro 1- Orientações Argumentativas dos comentários

\begin{tabular}{|c|c|}
\hline $\begin{array}{c}\text { Comentários - Grupo } 1 \\
\text { Argumentos favoráveis à implementação }\end{array}$ & $\begin{array}{c}\text { Comentários - Grupo } 2 \\
\text { Argumentos desfavoráveis à } \\
\text { implementação }\end{array}$ \\
\hline $\begin{array}{l}\text { 1. "PARABÉNS ao Ministro da Educação e ao } \\
\text { presidente, agora SIM, o aluno vai voltar a } \\
\text { Estudar de Verdade, sem Manipulação, sem } \\
\text { Militância e sem Ideologia de Gênero. Avante } \\
\text { meu Brasil [...]". (sic) }\end{array}$ & $\begin{array}{l}\text { 11. "Podia aumentar o número de IFs, mas } \\
\text { colégio militar não chega nem perto da } \\
\text { qualidade dos IFs. Colegio militar só serve } \\
\text { para aumentar a desigualdade na } \\
\text { educação." (sic) }\end{array}$ \\
\hline $\begin{array}{l}\text { 2. "Valorizar o professor e começar a } \\
\text { implantar a verdadeira disciplina em sala de } \\
\text { aula ... Postura." }\end{array}$ & $\begin{array}{l}\text { 12. "Militarização das escolas, qual o } \\
\text { propósito ideológico dessa medida? Vigiar } \\
\text { e disciplinar! Adeus criticidade e } \\
\text { pensamento livre." }\end{array}$ \\
\hline
\end{tabular}




\begin{tabular}{|c|c|}
\hline $\begin{array}{l}\text { 3. "Maravilhoso!!!! Colocar ordem nessa } \\
\text { educação!” }\end{array}$ & $\begin{array}{l}\text { 13. "Uma ilusão. O que falta é } \\
\text { investimento e não farda." }\end{array}$ \\
\hline 4. “Educação de qualidade.” & $\begin{array}{l}\text { 14. “Não à militarização da educação. } 0 \\
\text { sistema deveria proporcionar } \\
\text { equipamentos com pluralidade e } \\
\text { democracia [...]" }\end{array}$ \\
\hline $\begin{array}{l}\text { 5. "Parabéns tem que ser assim. Só assim vai } \\
\text { ter respeito pelos professores e pela nação." }\end{array}$ & $\begin{array}{l}\text { 15. "As escolas cívico-militares não é a } \\
\text { solução para o ensino no Brasil. Os } \\
\text { professores sim deveriam ser bem } \\
\text { remunerados." }\end{array}$ \\
\hline $\begin{array}{l}\text { 6. "Que todas as escolas adotem esse sistema. } \\
\text { Realmente, o brasileiro precisa entender a } \\
\text { importância da disciplina e da hierarquia." }\end{array}$ & $\begin{array}{l}\text { 16. "Antes de abrir essas escolas, cuidem } \\
\text { dos IFs, eles já são realidade, só precisam } \\
\text { da volta do investimento..." }\end{array}$ \\
\hline $\begin{array}{l}\text { 7. "Elegância e porte incríveis. Ambientes de } \\
\text { educação precisam disso." }\end{array}$ & $\begin{array}{l}\text { 17. "[...] olha o custo disso, será privilégio } \\
\text { para poucos, melhorem nossa educação } \\
\text { básica no Brasil inteiro que já vai ajudar } \\
\text { no futuro das nossas crianças." }\end{array}$ \\
\hline $\begin{array}{l}\text { 8. "Morei muitos anos ao lado de um Colégio } \\
\text { Militar e pude perceber a melhoria não só do } \\
\text { comportamento dos alunos mas também na } \\
\text { segurança dos arredores do colégio. Antes de } \\
\text { ser implantado, se tratava de um colégio } \\
\text { estadual. Havia muita circulação de drogas } \\
\text { [...] e falta de zelo pela estrutura do colégio." } \\
\text { (sic) }\end{array}$ & $\begin{array}{l}\text { 18. "Vocês estão sendo enganados, não são } \\
\text { escolas militares com todo aquele } \\
\text { orçamento de uma, são escolas públicas } \\
\text { militarizadas só pra impor disciplina e } \\
\text { moral e cívica [...]" (sic) }\end{array}$ \\
\hline $\begin{array}{l}\text { 9. “Acho excelente, são de ótima qualidades." } \\
\text { (sic) }\end{array}$ & $\begin{array}{l}\text { 19. "Institutos federais apresentam } \\
\text { melhores rendimentos acadêmicos e } \\
\text { menores custos." }\end{array}$ \\
\hline $\begin{array}{l}\text { 10. “[...] O problema é a indisciplina e o } \\
\text { sistema de ensino (passar sem o aluno ter } \\
\text { aprendido }[\ldots]) \text { " }\end{array}$ & $\begin{array}{l}\text { 20. “Com tantas escolas precisando de } \\
\text { investimento, porque caem em pedaços e } \\
\text { não possuem a estrutura mínima para os } \\
\text { alunos, o MEC quer investir nessas, que } \\
\text { em sua maioria, atendem uma elite } \\
\text { apenas.” (sic) }\end{array}$ \\
\hline
\end{tabular}

Fonte: Brasil (2019). Comentários na postagem.

\section{Um olhar à didatização: a lupa nos comentários}

É necessário que os alunos cultivem o olhar aos comentários, não simplesmente para se colocarem contrários ou favoráveis ao programa escolar ali difundido: é, fundamental apresentar razões para o ponto de vista, dadas as direções argumentativas. Os alunos serão provocados a separar os comentários em grupos.

Os comentários do grupo 1 apresentam argumentos favoráveis ao Programa, à implantação de novas escolas militares no País e fazem parte de um movimento enunciativo em que as direções argumentativas ressaltam os valores recorrentes das escolas militares, voltadas para as práticas de ordem e disciplina, além de 
consideradas modelo de qualidade e hierarquia, tidos como benéficos para a educação. Essa implementação, segundo os argumentos, está diretamente relacionada com a busca pelo estabelecimento da ordem e da disciplina nas escolas, e estes, para os favoráveis, são os sentidos que norteiam a argumentação presente nesse primeiro conjunto de comentários.

Uma primeira observação importante para se compreender a construção de sentido nesse grupo argumentativo e um possível processo de didatização do gênero diz respeito ao emprego de palavras como "ordem" e "disciplina" que se colocam na rede enunciativa construindo sentidos associados à menção às escolas militares, considerando os argumentos dos dois grupos.

Percebe-se que os comentários pertinentes ao grupo 1 e ao anúncio do programa ressaltam a escola militar relacionada incontestavelmente a esses valores. No comentário (2) "Valorizar o professor e começar a implantar a verdadeira disciplina em sala de aula ... Postura.", pode-se perceber a existência da ideia de que, através da implantação das escolas militares, haverá o respeito aos professores, bem como a disciplina, o que indica um dizer que considera a não presença dessa disciplina nas escolas convencionais ou as que pertencem aos institutos federais, escolas também mencionadas no grupo de argumentos que apresenta crítica ao modelo cívico-militar.

Além dessas considerações, observa-se no comentário (6), em que se utiliza o tipo textual injuntivo "Que todas as escolas adotem esse sistema. Realmente, o brasileiro precisa entender a importância da disciplina e da hierarquia", que, além da valorização da disciplina em visão generalizada, há o enaltecimento da hierarquia, em que se pode retomar a questão da hierarquia militar tomada como um argumento que influencia o aprendizado pelos alunos, conforme o comentário.

Outra forma observada nos comentários relativos ao grupo que defende a implantação das escolas militares, na visão do locutor que comenta, é a qualidade no ensino, como se observa em (1) "PARABÉNS ao Ministro da Educação e ao presidente, agora SIM, o aluno vai voltar a Estudar de Verdade [...]", ressaltando em outros comentários a qualidade das escolas militares. Ao mesmo tempo que sustenta a expressão "estudar de verdade", esse comentário direciona os leitores à ideia de que, no contexto atual das outras escolas, os alunos não estudam verdadeiramente. Vale problematizar, nessa direção, se os argumentos em (1) e (8) do grupo 1 de fato constituem seu papel argumentativo de ressaltar qualidades das escolas favoráveis às 
escolas cívico-militares, pois enunciativamente o que se destaca é um posicionamento contrário às escolas estaduais, descrevendo de maneira generalizada a presença de drogas nos arredores antes que essa se tornasse uma escola com o perfil defendido.

Tal polêmica pode ser objeto de discussão em sala, em que se avaliaria, por exemplo, as características ao termo "educação" em "educação de verdade", atribuídas à educação cívico-militar, seriam convenientes conforme o argumento defendido no grupo 1. Vale discutir com os alunos aspectos que ressaltem elementos que caracterizam tais escolas, destacando posturas que indicam posicionamentos diferentes sem conflitos, mas com posicionamentos justificados de maneira amadurecida. Tais aspectos devem ser elaborados oralmente com os alunos em geral e, em grupos, em escrita dissertativo-argumentativa, com o uso de conectivos que se encaixam na construção crítica dos posicionamentos, usando "por um lado [...] por outro lado", "porque”, “uma vez que”, “entretanto", "no entanto", “ora [...] ora”, "embora”, "ou [...] ou".

Quanto ao grupo 2 de argumentos desfavoráveis ao Programa das Escolas Cívico-Militares, os comentários estabelecem desdobramentos argumentativos contrários à implantação ou à expansão de escolas militares no País, justificando tal posicionamento pelo fato de que já existem escolas com potencial semelhante ao das escolas cívico-militares, solicitando a melhoria e o investimento de instituições de ensino já vigentes em escolas convencionais e em institutos federais, em vez de investir no programa em anúncio, como se observa em (16) "Antes de abrir essas escolas, cuidem dos IFs, eles já são realidade, só precisam da volta do investimento [...]", (19) "Institutos federais apresentam melhores rendimentos acadêmicos e menores custos" e em (20) "Com tantas escolas precisando de investimento, porque caem em pedaços e não possuem a estrutura mínima para os alunos, o MEC quer investir nessas, que em sua maioria, atendem uma elite apenas" (sic).

Observa-se também que o Programa, que visa à construção e à ampliação da rede de escolas militares, é criticado por buscar, através da militarização, a melhoria na educação, conforme se apresenta nos argumentos (12) e (14): (12) "Militarização das escolas, qual o propósito ideológico dessa medida? Vigiar e disciplinar! Adeus criticidade e pensamento livre." (14) "Não à militarização da educação. O sistema deveria proporcionar equipamentos com pluralidade e democracia [...]" 
Nota-se que nesses comentários palavras como "ordem" e "disciplina" são valores abordados com outros sentidos, referindo-se a um referencial histórico diferente daquele que fundamenta os sentidos que circulam nos comentários encontrados no grupo um. Nos comentários do grupo 2, contrários à militarização do ensino, os sentidos de ordem e disciplina destoam dos regramentos impostos e relacionam-se a pensamento livre, pluralidade e democracia; ressaltando outros sentidos para as expressões e reforçando o movimento enunciativo em questão, que indica os valores contrários à militarização e marcados por uma visão sobre educação que destoa do que associa o sentido de disciplina à repressão.

Outra consideração importante é o que se diz em (11) e (17), utilizando o tipo textual injuntivo: (11) "Podia aumentar o número de IFs, mas colégio militar não chega nem perto da qualidade dos IFs. Colegio militar só serve para aumentar a desigualdade na educação." (sic); (17) "[...] olha o custo disso, será privilégio para poucos, melhorem nossa educação básica no Brasil inteiro que já vai ajudar no futuro das nossas crianças."

Nesses comentários, ressalta-se a ideia da desigualdade na educação e chama-se atenção para os gastos, uma vez que as escolas militares, ao ser implantadas, gerarão custos e darão força a um sistema rígido de ingresso, tornando-se, segundo as argumentações em questão, uma forma de aumentar ainda mais as desigualdades na educação brasileira, uma vez que a seleção para compor o alunado poderá não contemplar alunos de classes desfavorecidas.

Pesa, desse modo, a historicidade que vincula o pensamento do grupo 1 a grupos que acreditam nos valores da disciplina e da soberania militar como solução, defendendo que, através da militarização (ou não) das escolas, será alcançada a melhoria na educação do País. Assim, a direção argumentativa de ambos os grupos desencadeia os conflitos originários da historicidade que constitui os sentidos sobre o sentido fundante de escola e o modo como a instituição se projeta nos sentidos. Vale deixar claro que a proposta de cada grupo credita ou não a eficiência escolar a uma rede de comportamentos que conduzem ao universo escolar idealizado

Vale enfatizar que a discussão é prenhe de sentidos e realçar que o debate sobre o funcionamento escolar não pode se transformar em briga ou desentendimento dos alunos na sala de aula. Dar força para o debate democrático na montagem dos argumentos $\mathrm{e}(\mathrm{m})$ escrita e seminário poderá fomentar o exercício da discussão e crítica plausivelmente elaborados, painel que é válido em um entendimento rico, 
apropriado para o exercício democrático da cidadania em sala de aula, proposta inclusive apoiada na discussão da Base Nacional Comum Curricular (BNCC).

\section{Considerações finais}

Podemos ler relacionando o todo com as partes ou as partes com o todo, e assim se dá a leitura à postagem. Os elementos para compreensão e interpretação se colocam de forma simultânea no processo de leitura, com a ressignificação da informação. Isso significa que o gênero provoca o posicionamento no processo de didatização como um todo repleto de sentidos, cujos elementos de significação se materializam em posicionamentos e argumentos que se produzem na cena enunciativa. No caso do gênero em foco, o referencial histórico como forma de produção de sentidos que cercam os acontecimentos nos dá pistas da complexidade das relações que precisam participar do cotidiano das aulas de língua portuguesa (linguagens) das quais o(a) professor(a) não pode se furtar, cabendo a ele/ela mediar temas que constituem a rotina dos cidadãos.

Em se tratando da visão enunciativo-discursiva, o tratamento ao gênero post é importante, no caso, porque traz imbricados ali um anúncio sobre um programa como investimento do Ministério da Educação, que aposta no programa de expansão das escolas cívico-militares, além dos comentários que mostram posições que os leitores assumem sobre o programa. Essa aposta que mescla olhares é tendência e traz marcas visíveis em direções argumentativas e discursos subjacentes para nossa observação.

Trabalhar com argumentação nos permite trazer vozes dos locutores que apoiam e dos que não apoiam o programa nos comentários da postagem. É possível que o(a) professor(a) explore essa riqueza de posições para compreender os caminhos da intrincada construção enunciativa que, de maneira significativa, é atravessada pelo político e pelas posições discursivas que ali se destacam.

No caso do gênero apresentado, formações como disciplina, soberania e militarização perpassam posições que os falantes produzem por meio desses comentários, evocando as forças argumentativas que ultrapassam a noção de argumentação como retórica.

A partir do presente estudo, apoiado na visão enunciativa relacionada a aspectos da vertente francesa de análise de discurso, pode-se perceber a força de duas 
direções argumentativas opostas nas redes sociais, indicando dois grupos que atribuem sentidos diferentes aos termos "ordem" e "disciplina", em seus pontos de vista favoráveis ou desfavoráveis à implantação e expansão das escolas com características militares.

Diante disso, o Programa anunciado e comentado de formas distintas nas redes sociais acaba por motivar a formação de dois grupos em que se mostram as orientações argumentativas opostas e conflitantes. É importante trabalhar com os dois grupos de argumentação, estabelecendo formas de os alunos se expressarem e registrarem seu posicionamento, traçando ou comparando visões no gênero redação escolar, visualizando a importância de expor, descrever e comparar posições em uma produção dissertativo-argumentativa.

Os comentários analisados traduzem direções argumentativas, em que argumentos são apresentados para que o alocutário (leitor) proceda à escrita para conclusão, no caso analisado, favorável ou contrária ao Programa e à implementação e expansão do grupo de escolas militares, o que implica justificar tal posicionamento com argumentos plausíveis.

Por isso, a função do professor é mediar a produção dos enunciados, compreendendo que se apoiam em discursos, valores e práticas partilhados na sociedade brasileira sobre o tema. A força enunciativa dos argumentos traz as forças contrárias das direções argumentativas que resvalam os valores que sustentam a instituição escolar atual: de um lado, apoia-se a prática de ensinar e aprender diretamente associada ao militarismo, à hierarquia e aos seus valores; de outro, há uma rede de argumentos que se sustentam pelo viés de rejeição à militarização da educação e das escolas, grupo que se baseia, portanto, em modelos convencionais de escola, como as estaduais, as privadas ou ainda os institutos federais, entendendo-as como fonte importante de investimento já presentes na sociedade brasileira.

\section{Referências}

BAKTHIN, Mikhail Mikhailovitch. Estética da criação verbal. São Paulo: Martins Fontes, 1992.

BRASIL. Escola Cívico Militar. Brasília, 5 set. 2019. Facebook: @ministeriodaeducação. Disponível em: 
https://www.facebook.com/ministeriodaeducacao/photos/a.516922078355611/24 29177957130004/?type=3\&theater. Acesso em: 12 ago. 2020.

DALMASCHIO, Luciani; JAMAL, Angela; A semântica da enunciação e seus princípios fundantes. In: PENA, E. (org.). Enunciação e língua: uma introdução. Florianópolis: Beconn, 2014. p. 17-27.

DIAS, Luiz Francisco. Sentido e enunciação: a atualidade do conceito de acontecimento na semântica. Estudos da Língua(gem), Vitória da Conquista, n. 1, v. 13, p. 229-248, jun. 2015.

DUCROT, Oswald. Argumentação retórica e argumentação linguística. Letras de Hoje, Porto Alegre, n. 1, v. 44, p. 20-25, jan./mar. 2009.

DUCROT, Oswald; CAREL, Marion. La semántica argumentativa: una introducción a la teoría de los bloques semánticos. Buenos Aires: Colihue, 2006.

GUIMARÃES, Eduardo.Semântica do Acontecimento: um estudo enunciativo da designação. Campinas: Pontes.2002.

GUIMARÃES, Eduardo. Argumentatividade e argumentação. Revista do Programa de Pós-Graduação em Letras da Universidade de Passo Fundo, Passo Fundo, n. 2, v. 9, p. 271-283, 2013.

MARCUSCHI, Luiz Antônio. Produção textual, análise de gêneros e compreensão. São Paulo: Parábola, 2008.

ORLANDI, Eni Pulcinelli. A linguagem e seu funcionamento: as formas do discurso. Campinas: Pontes, 2001.

ORLANDI, Eni Pulcinelli. Análise do discurso: princípios e procedimentos. Campinas: Pontes, 2009.

ORLANDI, Eni Pulcinelli. Discurso e argumentação: um observatório do político. Fórum Linguístico, Florianópolis, n. 1, p. 73-81, 1998. 